\title{
Detection of GI and GII noroviruses in drinking water and vegetables using filtration and real-time RT-PCR
}

\author{
Deshun Xu $\cdot$ Xiaofang Wu $\cdot$ Jiankang Han $\cdot$ Lei Ji $\cdot$ \\ Liping Chen $\cdot$ Xiaojuan Zhu $\cdot$ Yuehua Shen
}

Received: 17 March 2014 / Revised: 9 June 2014 / Accepted: 10 June 2014 / Published online: 27 June 2014

(c) The Author(s) 2014. This article is published with open access at Springerlink.com

\begin{abstract}
The purpose of the study was to provide a rapid and sensitive method for detecting NoV GI and NoV GII in drinking water and vegetables. The method is based on viral concentration by microporous membrane adsorption method before RNA extraction and real-time RT-PCR amplification. Then water and vegetable samples which artificially contaminated with NoV GI and GII stool samples were used to determine the mean virus recoveries and the method sensitivity. The method showed the detection limit of NoV GI was $4.13 \times 10^{2}$ copies $/ 500 \mathrm{~mL}$ for drinking water and $4.13 \times 10^{3}$ copies $/ 15 \mathrm{~g}$ for lettuce and coriander. The detection limit of NoV GII was $2.94 \times 10^{1}$ copies $/ 500 \mathrm{~mL}$ for distilled water, $2.94 \times 10^{2}$ copies $/ 500 \mathrm{~mL}$ for Mountain spring water and mineral water, and $2.94 \times 10^{3}$ copies $/ 15 \mathrm{~g}$ for lettuce and coriander. The method described provides a valuable tool for monitoring the potential public health risks associated with noroviruses contamination in drinking water and vegetables.
\end{abstract}

Keywords Detection $\cdot$ Human norovirus $\cdot$ Real-time RT-PCR $\cdot$ Drinking water $\cdot$ Vegetable

\section{Introduction}

Noroviruses (NoVs) are a major cause of infectious intestinal disease transmitted by food or water. The major

Deshun $\mathrm{Xu}$ and Xiaofang Wu have contributed equally to this work.

D. Xu $\cdot$ X. Wu $\cdot$ J. Han $\cdot$ L. Ji $\cdot$ L. Chen $(\bowtie) \cdot$ X. Zhu $\cdot$ Y. Shen

Huzhou Center for Disease Control and Prevention, 999

Changxing Road, Huzhou 313000, Zhejiang, China

e-mail: hzcdcwsw@126.com vehicles of transmission include shellfish, fruits, vegetables and water contaminated by fecal matter. NoVs are members of the Caliciviridae family and non-enveloped, icosahedral viruses about $27-35 \mathrm{~nm}$ in diameter containing a genome that is 7-7.5 kilobases of poly-adenylated, positive sense, single-stranded RNA [1]. NoVs have been divided into five genogroups, GI-GV [2]. GI and GII strains are human pathogens, the latter being detected more frequently throughout the world and predominant in outbreaks. $\mathrm{HuNoV}$ is the most frequent causes of foodborne diseases of viral etiology in the USA, causing over 5.4 million illnesses each year. Indirect transmission follows ingestion of contaminated food or water [3]. Estimates say that these viruses are responsible for $59 \%$ of all domestically acquired foodborne illnesses in the USA. NoVs are responsible for the major part $(99 \%)$ of these events causing annually an estimated 5.5 million foodborne illness cases [4]. Likewise, foodborne viruses are an important causative agent of foodborne outbreaks in Europe, causing $15.0 \%$ of all outbreaks. In the latter outbreaks, NoVs were the most important foodborne viruses [5].

Recently, the methods have used to recover NoVs by using polyethylene glycol (PEG) precipitation or ultracentrifugation for virus concentration. But, for different types of drinking water and vegetables matrices, several techniques combining various buffer solutions for concentration and purification have been evaluated and optimized [610]. So, we need to use different methods to detect NoVs in different types of food products. In this study, microporous membrane adsorption method followed by real-time reverse transcription was used for the detection of viruses from drinking water and vegetables, instead of time-consuming PEG precipitation method that uses complicated and varied buffer. The basic principle of this method is cellulose nitrate membrane of pore diameter $0.45 \mu \mathrm{m}$ filtration and 
ultrasonic elution. The aim of this study was to establish a universal method to recover and detect NoVs in vegetables and drinking water samples at the same time.

\section{Materials and methods}

\section{Virus samples}

Stool samples that tested positive for NoVs by electron microscope (EM) and RT-PCR were obtained from Zhejiang provincial center for disease control and prevention. Each stool sample was prepared by making a 1:10 (wt/vol) dilution in minimum essential medium (MEM)followed by thorough mixing and centrifugation at $3,000 \times g$ for $5 \mathrm{~min}$. Supernatants were used as virus samples and were stored at $-80{ }^{\circ} \mathrm{C}$ until use. The titers of the clarified fecal suspensions were established in NoV GI and NoV GII genomic copies with real-time RT-PCR standard curve obtained with the tenfold diluted in vitro RNA transcripts. The clarified suspension stocks of NoV GI and NoV GII had titers of approximately $4.13 \times 10^{5}$ genome copies $/ \mathrm{mL}$ and $2.94 \times 10^{5}$ genome copies $/ \mathrm{mL}$, respectively.

\section{Vegetables and drinking water sources}

Coriander and lettuce samples, collected randomly, were obtained from the market in Huzhou area. Each of the $15 \mathrm{~g}$ sample was put into the sterilized filter bag and artificially inoculated with NoV GI and GII before the experiments. The samples were stored at $4{ }^{\circ} \mathrm{C}$ prior to use. Water samples were obtained from different brands of bottled waters. These drinking waters were packaged in PVC bottles with a volume ranging from $250 \mathrm{ml}$ to 2 liter or were filled into 20-liter PVC barrels. These samples include bottled mineral water, bottled distilled water, and bottled Mountain spring water. All water samples were bought from a local grocery in Huzhou area, respectively, and surveys were taken at the time of purchase. Obtained water samples were stored at $4{ }^{\circ} \mathrm{C}$ prior to use.

\section{Concentration and recovery of NoVs}

For drinking water samples, $500 \mathrm{~mL}$ of Mountain spring water, mineral water, and distilled water were inoculated by direct application of $1 \mathrm{~mL}$ of viral dilution $\left(10^{-1}-10^{-5}\right)$. For vegetable samples, $15 \mathrm{~g}$ of coriander and lettuce were inoculated by direct application of $1 \mathrm{~mL}$ of viral dilution onto the vegetables surface. Inoculated samples were then allowed to incubate for $30 \mathrm{~min}$ at $37{ }^{\circ} \mathrm{C}$. And then $135 \mathrm{~mL}$ of MEM was added to the virus-inoculated vegetable samples and placed into a filter bag. The sample was then mixed in a stomacher at a normal velocity for $5 \mathrm{~min}$. The supernatant was collected and clarified by centrifugation at $3,500 \times g$ for $15 \mathrm{~min}$. The viral particles present in the water and vegetable samples were concentrated by the cellulose nitrate membrane of pore diameter $0.45 \mathrm{um}$ and $47-\mathrm{mm}$ diameter filtration (MILLIPORE, USA). Prior to the filtration process, $10 \mathrm{~mL}$ of $12.5 \mathrm{~mol} / \mathrm{L}$ $\mathrm{MgCL} 2$ was added, and the $\mathrm{pH}$ value was adjusted to 3.5 with $1 \mathrm{~mol} / \mathrm{L} \mathrm{HCL}$. The adjusted samples were passed through the filter, and then the filter membrane was cut into pieces, added $10 \mathrm{~mL}$ of $3 \%$ beef extract, next ultrasonic elution for $2 \mathrm{~min}$ $(75 \mathrm{~W})$, then centrifugation at $3,000 \times g$ for $15 \mathrm{~min}$, and the supernatants were used to extract Viral RNA (Fig. 1).

\section{Standard curve production}

The fragments of NoV GI and GII were cloned into PGEM-T easy vectors (Promega). And the plasmids were transformed into DH5a cells. Plasmids were purified with E.Z.N.A. Plasmid Miniprep Kit (Omega) and the concentrations were determined with the Biophotometer (Eppendorf). Estimation of the average molecular weight was performed, and the copy number was calculated, and then tenfold of its serial dilution was diluted. Standard curves were obtained for NoV GI and GII by testing the tenfold dilution $\left(10^{0}\right.$ to $\left.10^{10}\right)$ standard plasmid. The standard curves obtained from the mean $\mathrm{Ct}$ values of different viral concentrations were used for estimation of the recovered virus concentration in various samples.

\section{Nucleic acid extraction}

Nucleic acid extraction from the incubated samples and unspiked water samples (negative controls) was based on the Boom method using the High Pure Viral Nucleic Acid Kit (Roche), according to the manufacturer's instructions. $200 \mu \mathrm{L}$ samples were mixed with $200 \mu \mathrm{L}$ binding buffer supplemented with poly(A) and $50 \mu \mathrm{L}$ Proteinase $\mathrm{K}$ and then incubated for $10 \mathrm{~min}$ at $72{ }^{\circ} \mathrm{C}$. After several washes, RNA was eluted from the silica with $50 \mu \mathrm{L}$ of elution buffer and stored at $-80{ }^{\circ} \mathrm{C}$ or tenfold serially diluted for immediate amplification.

\section{Real-time RT-PCR}

The primers and probes (Table 1) were designed [11] using primer express 3.0 software for spanning ORF1 and ORF2 of norovirus. The oligonucleotides were synthesized, and the probes were labeled with FAM for GI NoV and VIC for GII NoV in TAKARA Corporation, Dalian. The realtime PCR was carried out using One Step Prime Script ${ }^{\circledR}$ RT-PCR Kit (Perfect Real Time) for duplex real-time RTPCR (TAKARA, Dalian). Briefly, the $25 \mu \mathrm{L}$ reaction mixture comprised $1 \times$ RT-PCR buffer, $2.5 \mathrm{U}$ EX Taq HS polymerase, $0.5 \mu \mathrm{L}$ RT Enzyme MixII, 400nM of each primers (GIF, GIR, GIIF, and GIIR), 100nM of each probes (GIP 
Fig. 1 Flow chart for virus detection
Inoculated water sample $500 \mathrm{~mL}$

Added MEM $135 \mathrm{~mL}$ to $15 \mathrm{~g}$ inoculated wegetable sample

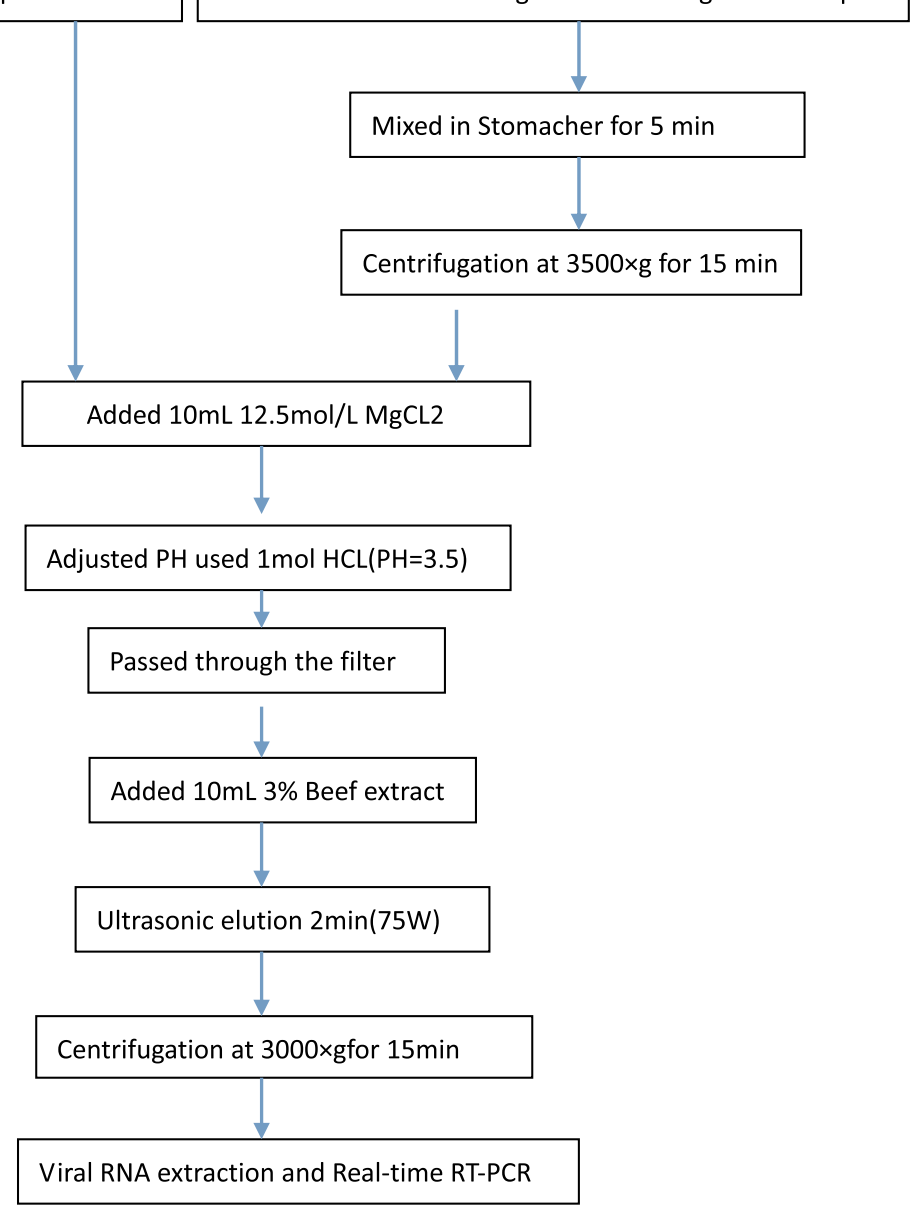

Table 1 Primers and probes used for real-time RT-PCR

\begin{tabular}{lll}
\hline Norovirus & oligonucleotides & Sequence $\left(5^{\prime}-3^{\prime}\right)$ \\
\hline GI & GIF & ATGTTCCGYTGGATGCGVTT \\
& GIR & CTTAGACGCCATCATCATTYAC \\
& GIP & FAM-AGGAGATYGCGATCYCCT- \\
& & GTCCAYA-TAMRA \\
GII & GIIF & ATGTTYAGRTGGATGAGRTTYT \\
& GIIR & TMGAYGCCATCWTCATTCAC \\
& GIIP & VIC-CACRTGGGAGGGCGATCG- \\
& & CAATC-TAMRA \\
\hline
\end{tabular}

and GIIP), and $5 \mu \mathrm{L}$ viral RNA. A 7500 Real-Time PCR (Applied Biosystems) was used. The reverse transcriptase step was run at $42{ }^{\circ} \mathrm{C}$ for $30 \mathrm{~min}$, followed by $95{ }^{\circ} \mathrm{C}$ for $5 \mathrm{~min}$ and 40 cycles of $95^{\circ} \mathrm{C}$ for $15 \mathrm{~s}$, and $57^{\circ} \mathrm{C}$ for $45 \mathrm{~s}$.

\section{Controls}

All precautions were taken to prevent false-positive or false-negative results. Amplifications were performed in different rooms, and filter-equipped pipette tips were used throughout the assay. All experiments were repeated at least three times, and a negative control sample (containing no nucleic acid) was run with each test.

\section{Results}

Quantification and standard curve of NoVS control

To confirm concentration of virus, the dynamic range and the sensitivity of the GI and GII norovirus quantification scheme were evaluated using the artificial GI and GII standard plasmids. The pairs of plasmids were quantified and diluted by tenfold serial magnitude from 1 copy to $1 \times 10^{10}$ copies per reaction. They were amplified by real-time RT-PCR and then analyzed by the ABI7500 Realtime System software. The results revealed the reliability of detecting less than 10 copies per reaction of NoV GI and GII plasmid DNA, and the assay showed excellent linearity between the log of target input and CT value, suggesting that the assay has a dynamic range of at least 10 logs and 
Fig. 2 The dynamic range and the sensitivity of the GI and GII norovirus assay. Left panel Amplification curve of standard plasmid $\left(10^{1}-10^{10}\right.$ copies) for GI (a) and GII (c) norovirus. Right panel Standard curve of GI $\left(\mathbf{b}, R^{2}=0.998\right.$, slope $=-3.19)$ and GII (c, $R^{2}=0.997$, slope $\left.=-3.21\right)$ norovirus
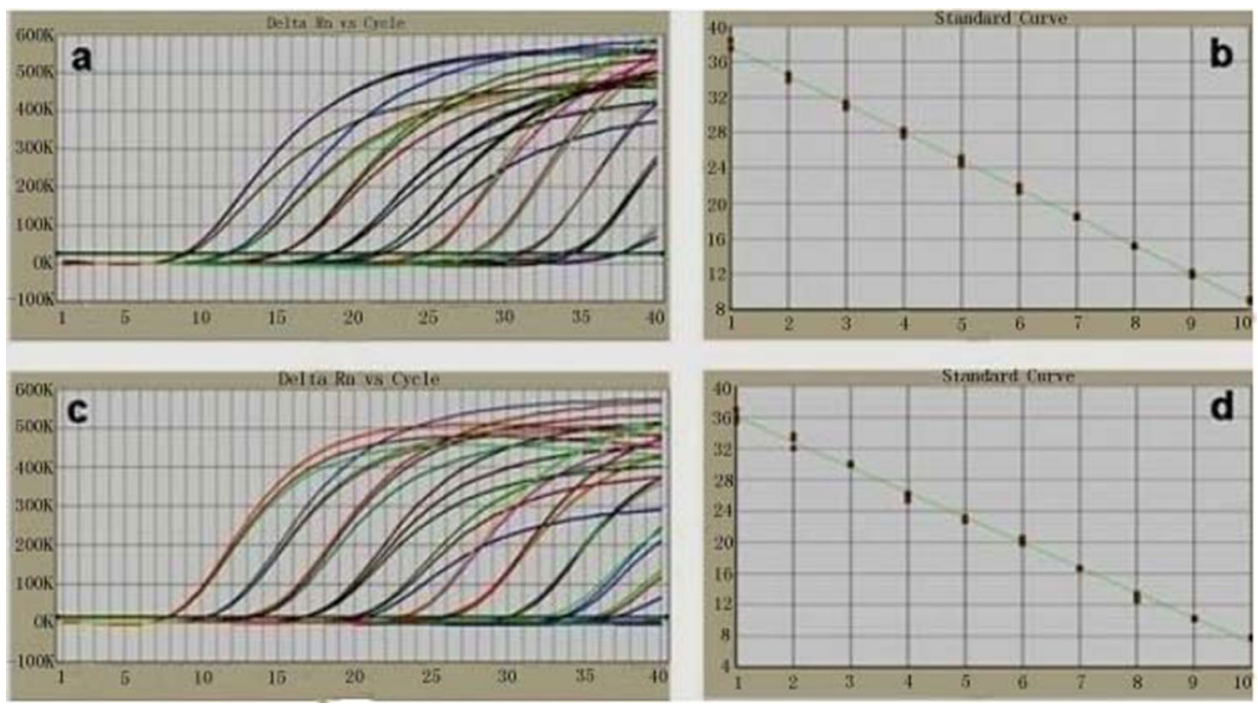

the correlation coefficient was 0.998 for GI NoV and 0.997 for GII NoV, respectively (Fig. 2). The linearity and co-efficiency indicate that the assay is reproducible and sensitive.

Detection of NoVs in drinking water

The new concentration method was applied to detect NoVs in different drinking water samples. The tested samples included mineral water, distilled water and Mountain spring water, all which were bought from local grocery in Huzhou area.

One $\mathrm{mL}$ of serial tenfold dilutions of $4.13 \times 10^{5}$ copies $/ \mathrm{mL}$ of NoV GI and $2.94 \times 10^{5}$ copies $/ \mathrm{mL}$ of NoV GII were inoculated into $500 \mathrm{~mL}$ of water samples, and then inoculated samples were performed following microporous membrane adsorption method. The result showed that the method could detect the particles of NoV GI at the original level of $4.13 \times 10^{2}$ copies $/ \mathrm{mL}$ in $500 \mathrm{~mL}$ of distilled water,Mountain spring water, and mineral water. The average recovery rates were $67.4-77.6 \%$ for distilled water, $38.5-47.2 \%$ for Mountain spring water, and 34.4-47.6\% for mineral water. The detection limits of NoV GII were $2.94 \times 10^{1}$ copies $/ \mathrm{mL}$ in $500 \mathrm{~mL}$ of distilled water sample and of Mountain spring water and mineral water were $2.94 \times 10^{2}$ copies $/ \mathrm{mL}$ in $500 \mathrm{~mL}$ water sample The average recovery rates were $65.2-79.1 \%$ for distilled water, $40.3-50.4 \%$ for mountain spring water, and $40.9-49.2 \%$ for mineral water (Table 2).

Detection of NVs in vegetables

The vegetable sources including coriander and lettuce samples were collected randomly from the markets in Huzhou area. These vegetables sources are frequently associated with non-bacterial foodborne gastroenteritis. These matrices were selected in order to compare the recovery of this method in different vegetables. There was no detection of virus in sample controls through all experiments.

One $\mathrm{mL}$ of serial tenfold dilutions of $4.13 \times 10^{5}$ copies/ $\mathrm{mL}$ of NoV GI and $2.94 \times 10^{5}$ copies/mL of NoV GII were inoculated into $15 \mathrm{~g}$ of coriander and lettuce. Inoculated samples were then allowed to incubate for $30 \mathrm{~min}$ at $37^{\circ} \mathrm{C}$. $135 \mathrm{~mL}$ of MEM was added to the virus-inoculated samples and placed into a filter bag, and then microporous membrane adsorption method was performed. The result showed that the method could detect the particles of NoV GI at the original level of $4.13 \times 10^{3}$ copies $/ \mathrm{mL}$ in $15 \mathrm{~g}$ of lettuce and coriander. The average recovery rates were $16.4-18.2 \%$ for lettuce and 16.3-19.1\% for coriander. The detection limits of NoV GII were $2.94 \times 10^{3}$ copies $/ \mathrm{mL}$ in $15 \mathrm{~g}$ of lettuce and coriander sample. The average recovery rates were 17.8 $20.1 \%$ for lettuce and $18.3-20.4 \%$ for coriander (Table 2).

Detection of NVs in drinking water and vegetable samples

The new concentration method was applied to detect NoVs in different drinking water and vegetable samples. The tested samples included mineral water (12 brands), distilled water ( 9 brands), mountain spring drinking water ( 20 brands), lettuce (13 brands), and coriander ( 8 brands), originated from local grocery and markets in Huzhou area. A total of 62 samples were assayed, and one copy of NoV GII was detected in mineral water. The rest of the tested samples were negative for NoVs-specific nucleic acids.

\section{Discussion}

Noroviruses are considered to be the leading cause of foodborne and waterborne disease outbreaks and acute nonbacterial gastroenteritis worldwide, with transmission from 
Table 2 Recovery of GI and GII in samples after inoculation

\begin{tabular}{|c|c|c|c|c|c|c|c|}
\hline \multirow[t]{2}{*}{ Sample } & \multirow[t]{2}{*}{ Dilution } & \multicolumn{2}{|c|}{ Concentration of GI (copies) ${ }^{\mathrm{a}}$} & \multirow[t]{2}{*}{ Recovery \% } & \multicolumn{2}{|c|}{ Concentration of GII (copies) } & \multirow{2}{*}{$\begin{array}{l}\text { Recovery } \\
\%\end{array}$} \\
\hline & & Inoculated & Recovered & & Inoculated & Recovered & \\
\hline \multirow[t]{5}{*}{ Distilled water } & $10^{-1}$ & $4.13 \times 10^{5}$ & $2.99 \times 10^{5}$ & $72.5 \pm 10.3^{\mathrm{b}}$ & $2.94 \times 10^{5}$ & $2.33 \times 10^{5}$ & $79.1 \pm 8.5$ \\
\hline & $10^{-2}$ & $4.13 \times 10^{4}$ & $3.2 \times 10^{4}$ & $77.6 \pm 13.2$ & $2.94 \times 10^{4}$ & $2.28 \times 10^{4}$ & $77.7 \pm 10.5$ \\
\hline & $10^{-3}$ & $4.13 \times 10^{3}$ & $2.78 \times 10^{3}$ & $67.4 \pm 12.4$ & $2.94 \times 10^{3}$ & $2.08 \times 10^{3}$ & $70.9 \pm 11.8$ \\
\hline & $10^{-4}$ & $4.13 \times 10^{2}$ & $2.92 \times 10^{2}$ & $70.6 \pm 11.2$ & $2.94 \times 10^{2}$ & $1.92 \times 10^{2}$ & $65.2 \pm 7.9$ \\
\hline & $10^{-5}$ & $4.13 \times 10^{1}$ & - & - & $2.94 \times 10^{1}$ & $2.11 \times 10^{1}$ & $71.6 \pm 14.2$ \\
\hline \multirow[t]{5}{*}{ Mountain spring water } & $10^{-1}$ & $4.13 \times 10^{5}$ & $1.95 \times 10^{5}$ & $47.2 \pm 12.4$ & $2.94 \times 10^{5}$ & $1.48 \times 10^{5}$ & $50.4 \pm 14.2$ \\
\hline & $10^{-2}$ & $4.13 \times 10^{4}$ & $2.04 \times 10^{4}$ & $49.4 \pm 13.1$ & $2.94 \times 10^{4}$ & $1.31 \times 10^{4}$ & $44.7 \pm 16.7$ \\
\hline & $10^{-3}$ & $4.13 \times 10^{3}$ & $1.57 \times 10^{3}$ & $38.5 \pm 17.5$ & $2.94 \times 10^{3}$ & $1.18 \times 10^{3}$ & $40.3 \pm 17.3$ \\
\hline & $10^{-4}$ & $4.13 \times 10^{2}$ & $1.78 \times 10^{2}$ & $43.2 \pm 10.5$ & $2.94 \times 10^{2}$ & $1.33 \times 10^{2}$ & $45.4 \pm 10.4$ \\
\hline & $10^{-5}$ & $4.13 \times 10^{1}$ & - & - & $2.94 \times 10^{1}$ & - & - \\
\hline \multirow[t]{5}{*}{ Mineral water } & $10^{-1}$ & $4.13 \times 10^{5}$ & $1.97 \times 10^{5}$ & $47.6 \pm 19.5$ & $2.94 \times 10^{5}$ & $1.45 \times 10^{5}$ & $49.2 \pm 15.7$ \\
\hline & $10^{-2}$ & $4.13 \times 10^{4}$ & $1.42 \times 10^{4}$ & $34.4 \pm 14.9$ & $2.94 \times 10^{4}$ & $1.26 \times 10^{4}$ & $42.8 \pm 13.2$ \\
\hline & $10^{-3}$ & $4.13 \times 10^{3}$ & $1.73 \times 10^{3}$ & $41.9 \pm 15.3$ & $2.94 \times 10^{3}$ & $1.20 \times 10^{3}$ & $40.9 \pm 14.1$ \\
\hline & $10^{-4}$ & $4.13 \times 10^{2}$ & $1.80 \times 10^{2}$ & $43.7 \pm 12.6$ & $2.94 \times 10^{2}$ & $1.36 \times 10^{2}$ & $46.2 \pm 12.4$ \\
\hline & $10^{-5}$ & $4.13 \times 10^{1}$ & - & - & $2.94 \times 10^{1}$ & - & - \\
\hline \multirow[t]{5}{*}{ Lettuce } & $10^{-1}$ & $4.13 \times 10^{5}$ & $7.31 \times 10^{4}$ & $17.6 \pm 5.6$ & $2.94 \times 10^{5}$ & $5.23 \times 10^{4}$ & $17.8 \pm 4.2$ \\
\hline & $10^{-2}$ & $4.13 \times 10^{4}$ & $7.52 \times 10^{3}$ & $18.2 \pm 4.4$ & $2.94 \times 10^{4}$ & $5.91 \times 10^{3}$ & $20.1 \pm 3.4$ \\
\hline & $10^{-3}$ & $4.13 \times 10^{3}$ & $6.77 \times 10^{2}$ & $16.4 \pm 5.4$ & $2.94 \times 10^{3}$ & $5.50 \times 10^{2}$ & $18.7 \pm 6.3$ \\
\hline & $10^{-4}$ & $4.13 \times 10^{2}$ & - & - & $2.94 \times 10^{2}$ & - & - \\
\hline & $10^{-5}$ & $4.13 \times 10^{1}$ & - & - & $2.94 \times 10^{1}$ & - & - \\
\hline \multirow[t]{5}{*}{ Coriander } & $10^{-1}$ & $4.13 \times 10^{5}$ & $7.89 \times 10^{4}$ & $19.1 \pm 3.1$ & $2.94 \times 10^{5}$ & $6.38 \times 10^{4}$ & $18.3 \pm 2.1$ \\
\hline & $10^{-2}$ & $4.13 \times 10^{4}$ & $6.73 \times 10^{3}$ & $16.3 \pm 4.3$ & $2.94 \times 10^{4}$ & $6.00 \times 10^{3}$ & $20.4 \pm 4.5$ \\
\hline & $10^{-3}$ & $4.13 \times 10^{3}$ & $7.10 \times 10^{2}$ & $17.2 \pm 8.5$ & $2.94 \times 10^{3}$ & $5.70 \times 10^{2}$ & $19.4 \pm 3.1$ \\
\hline & $10^{-4}$ & $4.13 \times 10^{2}$ & - & - & $2.94 \times 10^{2}$ & - & - \\
\hline & $10^{-5}$ & $4.13 \times 10^{1}$ & - & - & $2.94 \times 10^{1}$ & - & - \\
\hline
\end{tabular}

a Inoculated, recovered, and quantified by real-time RT-PCR

b Triplicates of three independent experiments

food and water or from person to person via the fecal-oral route affecting adults and children all over the world [12]. Indeed, NoVs cause at least $95 \%$ of all non-bacterial gastroenteritis outbreaks and $50 \%$ of all gastroenteritis outbreaks [13]. Moreover, waterborne transmission is a significant route of exposure, as contaminated water also serves as a vehicle for outbreaks of food poisoning by foods such as vegetables and shellfish. Therefore, in order to monitor the presence of enteric viruses, there is a need to develop better methods for virus recovery from a range of freshly produced items. This work presents an optimized methodology for sensitive and accurate detection of NoV GI and GII from drinking water and vegetable surfaces that consists of viral elution from the vegetable surface, concentration by microporous membrane adsorption concentrating method and real-time RT-PCR.

It was well known that there were only a few virus particles present in drinking water and vegetables. It is essential to establish a method to concentrate viruses efficiently from the drinking water and vegetables samples. Previously, studies have demonstrated that a positively charged filter membrane possesses a high ability to recover polioviruses from water samples $(>60 \%)[14,15]$. Based on these findings, the adsorption-elution-concentration method was developed for NoVs concentration and was widely used. However, it was latter revealed that this adsorptionelution-concentration method recovered NoVs inefficiently, and the detection limit in seeding experiment was two orders of magnitude less sensitive than the RT-PCR detection limit for virus samples[16]. As we found in our laboratory, by using the microporous membrane adsorption concentrating method, the detection limits of NoV GI and GII were $4.13 \times 10^{2}$ and $2.94 \times 10^{1}$ copies $/ \mathrm{mL}$ in $500 \mathrm{~mL}$ seeded distilled water sample, and $4.13 \times 10^{2}$ copies $/ \mathrm{mL}$ and $2.94 \times 10^{2}$ copies $/ \mathrm{mL}$ in $500 \mathrm{~mL}$ seeded Mountain spring water and mineral water sample, respectively. The detection limits of NoV GI and GII were $4.13 \times 10^{3}$ copies $/ \mathrm{mL}$ and $2.94 \times 10^{3}$ copies $/ \mathrm{mL}$ in $15 \mathrm{~g}$ seeded coriander 
and lettuce sample, respectively. The detection limit of this new protocol in seeding experiment is at least one order of magnitude for NoV GI and NoV GII per one liter seeded water. For detection in $15 \mathrm{~g}$ seeded vegetables, there are two orders of magnitude between the seeded virus and the detection result for both NoV GI and NoV GII. Our laboratory showed a high analytical sensitivity, as determined by the reliable detection for NoV genogroups I and II from the drinking water and vegetables samples. However, it is important to note that this does not reflect the sensitivity of the assay for viral RNA, since fragments of NoVs cloned into DNA plasmids were used to evaluate the sensitivity of the assay and possible losses of viral RNA during the nucleic acid extraction and incomplete transcription to cDNA during the RT reaction will occur. Nonetheless, we believe that the use of standard curves obtained from NoV GI and GII by testing the tenfold dilution standard plasmid for evaluation of the recovered virus concentration in various samples is valid and allows a comparison with other published assays.

Our new concentrating method has a high ability to recover NoVs from water samples and vegetables. There are several advantages of our newly established method. First, the viruses are not adsorbed to a positively charged filter membrane as in the current method, but rather are adsorbed to the ordinary cellulose nitrate membrane of pore diameter $0.45 \mu \mathrm{m}$. The procedure is relatively inexpensive, labor intensive and time-consuming. No special materials or equipment, such as charged membrane filters and multiple vacuum filtration apparatus, are required. Second, we use the acidic conditions to enhance the elution to promote the recovery yields from the membrane, no complex reagents and complex procedures. Third, current method was suitable for large volume water sample, which was not suitable for routine monitoring $[15,17]$. Therefore, our study demonstrates that the approach is a rapid, simple, and efficient way to concentrate NoVs and that the procedure is more sensitive but consumes less time and is less expensive.

To be of optimum practical application, the method used must meet the following criteria [18]: (1) be technically easy to accomplish in a short time; (2) have a high virus recovery rate; (3) concentrate a large range of viruses; (4) provide a small volume of concentrate; (5) not be costly; (6) be capable of processing large volumes of water; and (7) be repeatable (within a laboratory) and be reproducible (between laboratories). But there is no single method which fulfills all these requirements. Our method is far from perfect. One limitation is that suspended matter tends to clog the filters, so the volume of processed water is limited and the processing time is prolonged; when detecting the marked samples, we also encountered clogged filters, especially in heavily polluted samples. If necessary, we replace the clogged cellulose nitrate membrane. Moreover, it is not clear if this method effectively recovers other enteric viruses, which are also present in drinking water. The World Health Organization has referred to enteric viruses in drinking water quality guidelines, but did not specify which viruses should be monitored and what levels of viruses are acceptable [19]. It is important to quantify the viral contamination levels in drinking water in order to evaluate the risk of viral gastroenteritis and to prevent it.

In conclusion, the results of this study demonstrate that the microporous membrane adsorption method is a rapid, effective, and inexpensive method to concentrate NoVs from drinking water and vegetables. It would be a valuable method for the monitoring of potential public health risks associated with NoVs contamination in drinkable water and food products.

\section{Conflict of interest None.}

Compliance with Ethics Requirements This article does not contain any studies with human or animal subjects.

Open Access This article is distributed under the terms of the Creative Commons Attribution License which permits any use, distribution, and reproduction in any medium, provided the original author(s) and the source are credited.

\section{References}

1. Green K (2007) Caliciviridae: the noroviruses. Fields virology. Lippincott Williams \& Wilkins, Philadelphia

2. Vinje J, Hamidjaja RA, Sobsey MD (2004) Development and application of a capsid VP1 (region D) based reverse transcription PCR assay for genotyping of genogroup I and II noroviruses. J Virol Methods 116:109-117

3. Kotwal G, Cannon JL (2014) Environmental persistence and transfer of enteric viruses. Sci Direct 4:37-43

4. Scallan E, Hoekstra RM, Angulo FJ, Tauxe RV, Widdowson MA, Jones JL, Roy SL, Griffin PM (2011) Foodborne illness acquired in the United States-major pathogens. Emerg Infect Dis 17:7

5. EFSA (2012) The European Union summary report on trends and sources of zoonoses, zoonotic agents and food-borne outbreak sin the European Union in 2010. EFSA J 10. www.efsa.europa. eu/efsajournal. Accessed 16 Apr 2012

6. Baert L, Uyttendaele M, Debevere J (2008) Evaluation of viral extraction methods on a broad range of ready-to-eat foods with conventional and real-time RT-PCR for norovirus GII detection. Int J Food Microbiol 123:101-108

7. Guevremont E, Brassard J, Houde A, Simard C, Trottier YL (2006) Development of an extraction and concentration procedure and comparison of RT-PCR primer systems for the detection of hepatitis A virus and norovirus GII in green onions. J Virol Methods 134:130-135

8. Schultz AC, Saadbye P, Hoorfar J, Norrung B (2007) Comparison of methods for detection of norovirus in oysters. Int $\mathrm{J}$ Food Microbiol 114:352-356

9. Calguaa B, Rodriguez-Manzanoa J, Hundesaa A, Sunenb E, Calvoc M, Bofill-Masa S, Gironesa R (2013) New methods for the concentration of viruses from urban sewage using quantitative PCR. J Virol Methods 187:215-221 
10. De Keuckelaere A, Stals A, Baert L, Uyttendaele M (2013) Performance of two real-time RT-PCR assays for the quantification of GI and GII noroviruses and hepatitis a virus in environmental water samples. Food Anal Methods 6:1016-1023

11. Jothikumar N, Lowther JA, Henshilwood K, Lees DN, Hill VR, Vinje J (2005) Rapid and sensitive detection of noroviruses by using TaqMan-based one-step reverse transcription-PCR assays and application to naturally contaminated shellfish samples. Appl Environ Microbiol 71(4):1870-1875

12. Koo HL, Ajami N, Atmar RL, DuPont HL (2010) Noroviruses: the leading cause of gastroenteritis worldwide. Discov Med 10:61-70

13. Karst SM (2010) Pathogenesis of noroviruses, emerging RNA viruses. Viruses 2:748-781

14. Sobsey MD, Jones BL (1979) Concentration of poliovirus from tap water using positively charged microporous filters. Appl Environ Microbiol 37:588-595
15. Sobsey MD, Glass J (1980) Poliovirus concentration from tap water with electropositive adsorbent filters. Appl Environ Microbiol 40:201

16. Gilgen M, Germann D, Luthy J, Hubner P (1997) Three-step isolation method for sensitive detection of enterovirus, rotavirus, hepatitis A virus, and small round structured viruses in water samples. Int J Food Microbiol 37:189-199

17. Cho M-G, Jeong H-M, Ahn J-B, Kim K-Y (2011) Detection of feline calicivirus as norovirus surrogate in food and water sources using filtration and real-time RT-PCR. Food Sci Biotechnol 20(6): $1475-1480$

18. Block JC, Schwartzbrod L (1989) Viruses in water systems. Detection and Identification. VCH Publishers, New York

19. Grabow WOK, Taylor MB, De Villiers JC (2001) New methods for the detection of viruses: call for review of drinking water quality guidelines. Water Sci Technol 43:1-8 